\title{
Safety and Applicability of Continuous Retrograde Cardioplegia in Minimally Invasive Aortic Valve Replacement: New Approaches
}

\author{
Shunsuke Sato, MD, ${ }^{1}$ Takashi Azami, MD, PhD, ${ }^{1}$ Tatsuya Kawamoto, MD, \\ Kyozo Inoue, MD, PhD, ${ }^{1}$ and Kenji Okada, $\mathrm{MD}, \mathrm{PhD}^{2}$
}

\begin{abstract}
Purpose: To discuss minimally invasive cardiac surgery aortic valve replacement (MICS-AVR) approach via anterior thoracotomy using continuous retrograde cardioplegia. Continuous retrograde cardioplegia facilitates excellent continuous homogeneous cooling of the heart during cardiac arrest.

Methods: We performed AVR using the proposed method in nine patients between June 2018 and September 2019. The median age of the patients was 73 (range: 43-84) years. The pleural space was entered via anterior thoracotomy. After opening of the right atrium, a retrograde cardioplegic cannula was inserted into the coronary sinus with a purse-string suture. Continuous cold blood retrograde cardioplegia was initiated at $700 \mathrm{~mL} / \mathrm{h}$.

Results: Extubation in the operating room was performed in five $(56 \%)$ patients. No new decreased function of the left and right ventricles was observed in intraoperative transesophageal echography or transthoracic echocardiogram.

Conclusion: MICA-AVR through continuous retrograde cardioplegia is a safe technique.
\end{abstract}

Keywords: minimally invasive cardiac surgery aortic valve replacement, superior vena cava, inferior vena cava

\section{Introduction}

There are some disadvantages of minimally invasive cardiac surgery aortic valve replacement (MICSAVR) through thoracotomy. For instance, it leads to

${ }^{1}$ Department of Cardiovascular Surgery, Yodogawa Christian Hospital, Osaka, Osaka, Japan

${ }^{2}$ Department of Cardiovascular Surgery, Kobe University Graduate School of Medicine, Kobe, Hyogo, Japan

Received: September 15, 2020; Accepted: May 30, 2021 Corresponding author: Shunsuke Sato. Department of Cardiovascular Surgery, Yodogawa Christian Hospital, 1-7-50 Kunijima, Higashiyodogawa-ku, Osaka, Osaka 533-0024, Japan

Email: satosyun@ outlook.com

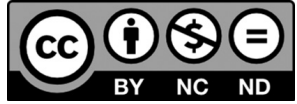

This work is licensed under a Creative Commons Attribution-NonCommercialNoDerivatives International License.

(C)2021 The Editorial Committee of Annals of Thoracic and Cardiovascular Surgery complications, such as selective cardioplegic perfusion and difficulty in tying down the biological valve to the aortic annulus. This study aimed to discuss MICS-AVR via anterior thoracotomy through continuous retrograde cardioplegia. Continuous retrograde cardioplegia facilitates excellent continuous homogeneous cooling of the heart during cardiac arrest. ${ }^{1)}$

\section{Materials and Methods}

We performed MICS-AVR using the proposed method in nine patients between June 2018 and September 2019. The median age of the patients was 73 (range: 43-84) years. We obtained IRB approval (number of IRB approval: No: 2020-019) on June 9, 2020.

\section{Operative procedure}

The right upper part of the patient's body was slightly bolstered, and both the arms were placed along the side 
of the body. Under general anesthesia with transesophageal echocardiography monitoring and one-lung ventilation, the pleural space was entered via the third intercostal space by cutting the fourth costal cartilage. If ascending aortic cannulation or replacement of the ascending aorta was required, the third costal cartilage was cut. In female patients, we could enter the third intercostal space via the submammary sulcus using epifascial exfoliate.

The heart and aorta were moved closer to the right anterior chest wall by pulling up of the pericardium, which is similar to the Yamazaki's Stonehenge technique. ${ }^{2)}$ Patients whose ascending aorta was located to the left of the midline (Fig. 1) and those with a relatively short distance between the sternum and vertebra could be treated without any difficulties. The right lung was separated from the operative field using the pericardium and traction strings thereafter, and one-lung ventilation was then discontinued.

Cardiopulmonary bypass was performed via femoral/ ascending aorta cannulation with 20Fr cannula (femoral; Medtronic, Mineapolis, MN, USA, ascending aorta; Mera) and femoral drainage with $25 \mathrm{Fr}$ cannula. Superior vena cava (SVC) drainage with 20 or $22 \mathrm{Fr}$ flexible $\mathrm{L}$-shape cannula was established via incision. The blood temperature was cooled to $34^{\circ} \mathrm{C}$.

Tapes were placed around the SVC and the inferior vena cava (IVC). A vent tube was inserted via the right upper pulmonary vein. Antegrade cardioplegic cannula was placed in the ascending aorta.

The ascending aorta was clamped, and cardiac arrest was induced with cold antegrade cardioplegia $\left(9^{\circ} \mathrm{C}\right)$.

After opening of the right atrium, a retrograde cardioplegic cannula was inserted into the coronary sinus with a
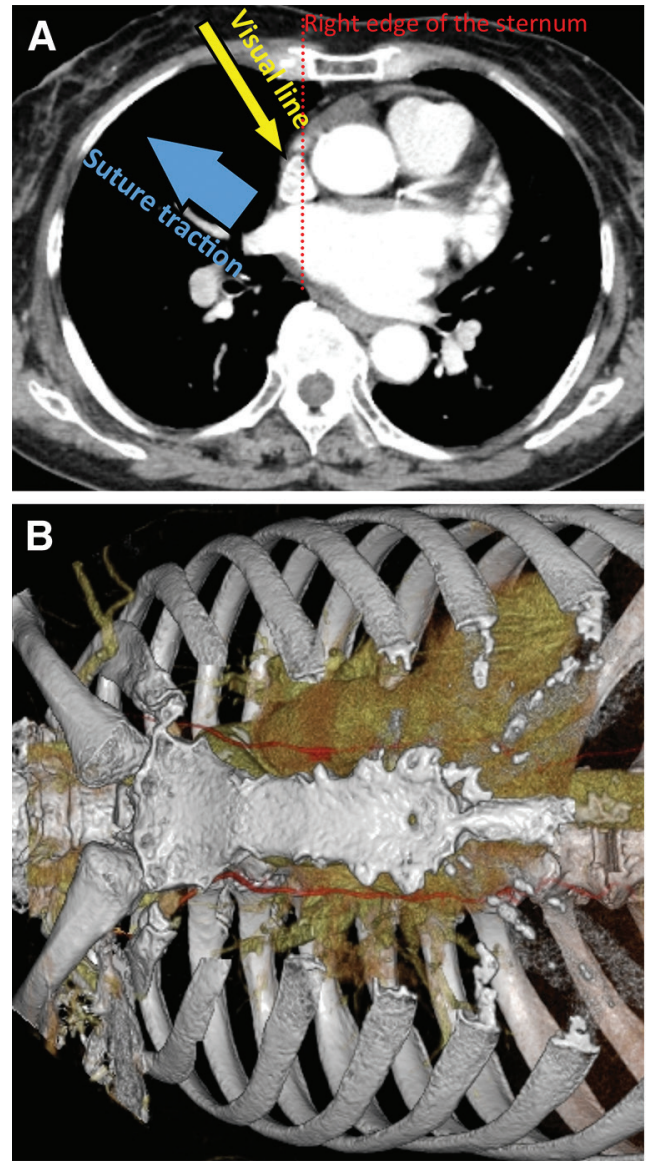
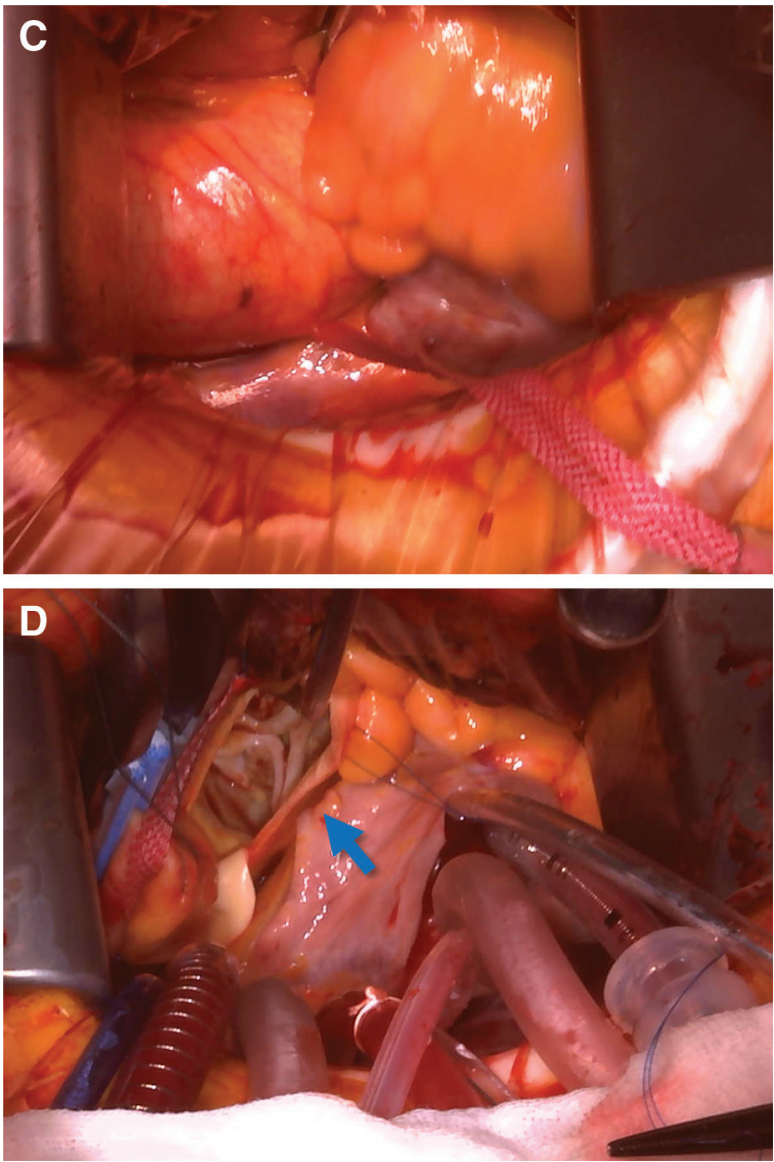

Fig. 1 (A) Even in cases where the aorta was located slightly to the left of the sternum, the operative field was still good with anterior intercostal thoracotomy and pericardial traction. (B) Same patient, on three-dimensional computed tomography scan, the ascending aorta was not observed from the right side of the sternum. (C) and (D) Same patient, we could obtain a good operative field with suture traction and twisting of the upper body. 
purse-string suture. A balloon catheter was utilized for retrograde cardioplegic cannula and was placed as shallow as possible in the coronary sinus using purse-string suture. Continuous cold blood retrograde cardioplegia was initiated in $700 \mathrm{~mL} / \mathrm{h}$. After opening the aorta, it was found that there was sufficient backflow from the coronary ostia and it was red, not black. If the backflow was inadequate, the flow rate of retrograde cardioplegic fluid was increased.

The composition of undiluted cardioplegia is described below: sodium ion, $132 \mathrm{mEq} / \mathrm{L}$; potassium ion, $52 \mathrm{mEq} / \mathrm{L}$; calcium ion, $2.2 \mathrm{mEq} / \mathrm{L}$; $\mathrm{HCO}^{-}, 50 \mathrm{mEq} / \mathrm{L}$ (theoretical values); and $\mathrm{pH}, 7.8$ (the actual measurement value). In continuous retrograde cardioplegia, the ratio of undiluted cardioplegia to blood was 1:5. The infusion pressure of retrograde cardioplegia was $<40$ mmHg. The solution temperature was $9^{\circ} \mathrm{C}$.

AVR was performed in a similar manner. During aortic valve replacement, antegrade cardioplegic cannula was set aside. After providing warm cardioplegia $\left(38^{\circ} \mathrm{C}\right)$, the aortic clamp was removed.

The resected costal cartilage was fixed with a monofilament absorbent suture.

\section{Results}

Extubation in the operating room was performed in five $(56 \%)$ patients (Table 1). None of the cases had to wait specifically for the recovery of cardiac function until weaning from cardiopulmonary bypass, and no case required defibrillation after aortic declamping. None of the cases required intra-aortic balloon pumping or percutaneous cardiopulmonary support. No new decreased function of left and right ventricles was observed in intraoperative transesophageal echography or postoperative transthoracic echocardiogram or pressure data at the intensive care unit entry (Table 2). One patient required return cardiac arrest due to perivalvular leakage. As the number of cases increased, the number of muscle fiber cuts decreased due to the reduction in the wound and the incision along the muscle fibers, and postoperative creatine kinase (CK) rise was suppressed.

\section{Discussion}

There is no report of MICS-AVR using continuous retrograde cardioplegia. Continuous retrograde cardioplegia is the rational approach in MICS-AVR. There are two advantages of retrograde cardioplegia. One, complications due to selective cardioplegia ${ }^{3,4)}$ are prevented, and two, it is useful for de-airing.

There are two advantages of continuous cardioplegia. One, it is excellent in terms of myocardial protection. For example, Louagie et al. ${ }^{5)}$ reported that continuous

Table 1 The patient characteristics

\begin{tabular}{|c|c|c|c|c|c|c|c|c|c|c|c|c|}
\hline No. & $\begin{array}{l}\text { Age } \\
(y)\end{array}$ & Sex & AR/AS & $\begin{array}{l}\text { Cannula- } \\
\text { tion }\end{array}$ & $\begin{array}{l}\text { OP time } \\
(\min )\end{array}$ & $\begin{array}{c}\text { CPB } \\
(\min )\end{array}$ & $\underset{(\min )}{\mathbf{A x}}$ & $\begin{array}{l}\text { CK-MB } \\
(\mathrm{ng} / \mathrm{mL})\end{array}$ & $\begin{array}{c}\text { CK } \\
(\mathrm{ng} / \mathrm{mL})\end{array}$ & $\begin{array}{l}\text { Trans- } \\
\text { fusion }\end{array}$ & Extubation & $\begin{array}{l}\text { Discharge } \\
\text { (days after } \\
\text { operation) }\end{array}$ \\
\hline 1 & 71 & Female & AS & FA & 370 & 211 & 144 & 26 & 426 & + & ICU & 8 \\
\hline 2 & 43 & Male & $\mathrm{AR}$ & FA & 305 & 183 & 93 & 65 & 3129 & - & $\begin{array}{l}\text { Operative } \\
\text { theater }\end{array}$ & 14 \\
\hline 3 & 77 & Male & AS & AscAo & 365 & 228 & 135 & 57 & 2568 & - & $\begin{array}{l}\text { Operative } \\
\text { theater }\end{array}$ & 11 \\
\hline 4 & 78 & Female & AS & AscAo & 525 & 332 & $\begin{array}{c}196+ \\
65^{*}\end{array}$ & 67 & 2088 & + & ICU & 23 \\
\hline 5 & 71 & Female & AS & FA & 273 & 175 & 111 & 55 & 377 & - & $\begin{array}{l}\text { Operative } \\
\text { theater }\end{array}$ & 11 \\
\hline 6 & 74 & Male & $\mathrm{AR}$ & FA & 226 & 125 & 69 & 35 & 369 & - & $\begin{array}{l}\text { Operative } \\
\text { theater }\end{array}$ & 10 \\
\hline 7 & 84 & Female & AS & FA & 284 & 188 & 117 & 30 & 336 & + & ICU & 25 \\
\hline 8 & 49 & Male & AR & FA & 294 & 201 & 108 & 36 & 1410 & - & ICU & 8 \\
\hline 9 & 59 & Male & AR & FA & 229 & 141 & 78 & 36 & 383 & - & $\begin{array}{l}\text { Operative } \\
\text { theater }\end{array}$ & 8 \\
\hline
\end{tabular}

No. reflects the order of operation.

*Return cardiac arrest was required due to perivalvular leakage.

AR: aortic regurgitation; AS: aortic stenosis; AscAo: ascending aorta; Ax: cardiac arrest time; CK: creatine kinase immediately after finishing the operation; CPB: cardiopulmonary bypass time; FA: femoral artery; ICU: intensive care unit; OP time: operation time 


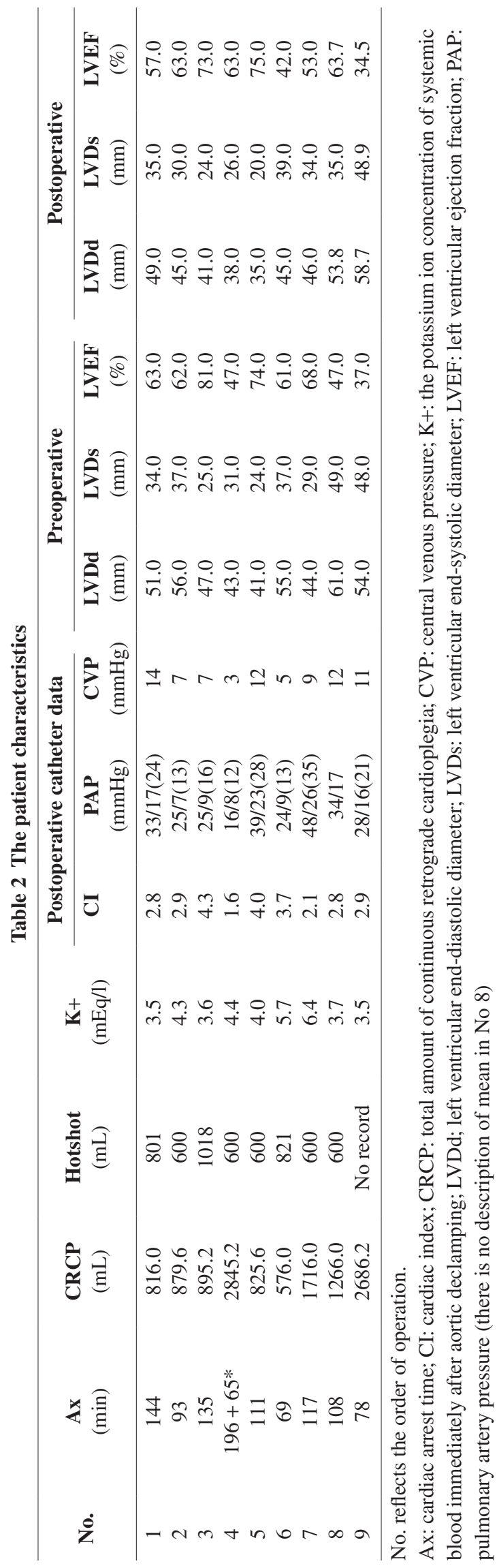

cold blood cardioplegia results in fewer cardiac events, better left ventricular performance, and a marked improvement of the right ventricular function when compared with similar solutions of blood cardioplegia administered intermittently, independent of their means of delivery.

In Louagie's study, the infusion speed of continuous retrograde cardioplegia was $50 \mathrm{~mL} / \mathrm{min}$; however, our target amount of continuous cardioplegia showed approximately $700 \mathrm{~mL} / \mathrm{h}$, which is the same as the additional amount of intermittent cardioplegia per hour. It is presumed to be sufficient for cooled myocardium. We believe that excessive cardioplegia may cause myocardial edema. According to Higami et al., ${ }^{6}$ the amount of continuous retrograde cold cardioplegia perfused per left ventricular mass weight (LVMW) was significantly correlated with mitochondrial damage. This study is a model performed by a method of cardioplegia similar to our study, wherein the right ventricular myocardium was biopsied and mitochondrial damage was observed using an electron microscope. In cases where cold cardioplegia was administered at $5 \mathrm{~mL} / 100 \mathrm{~g} \mathrm{LVMW} /$ minute or higher, mitochondria with irreversible damage were not observed. ${ }^{\text {) }}$

The average left ventricular myocardial weight in the Japanese population is estimated to be $133 \pm 28 \mathrm{~g}$ for men and $105 \pm 22 \mathrm{~g}$ for women ${ }^{7}$; accordingly, the preferable amount of average retrograde continuous cold cardioplegia is approximately $665 \mathrm{~mL} / \mathrm{h}$ for men and $525 \mathrm{~mL} / \mathrm{h}$ for women.

No new decreased function of left and right ventricle was observed in our series. In a past study, right heart failure due to retrograde cardioplegia was reported to occur as a perfusion failure of the middle cardiac vein due to too deep placement when placed blindly.

The other advantage is that the operation was not interrupted by intermittent cardioplegia.

During continuous retrograde cardioplegia, there is a blood outflow from the coronary ostium, but it does not significantly disturb the view of the operation at the flow velocity used. In addition, we could discontinue retrograde cardioplegia for a short duration. In MICS, CK is generally high because it involves muscle incision, and CK-MB is also high due to dragging. There are no cases in which CK-MB has an especially high value when compared with CK.

Anterior thoracotomy via cutting of the costal cartilage allows easy ascending cannulation, and direct 
insertion of retrograde cardioplegia cannula into the coronary sinus via the right atriotomy causes trouble-free cardioplegia.

The following are the advantages of this type of surgery: this approach is similar to or even more convenient than partial sternotomy; it can be applied easily to a patient with aortic regurgitation who requires retrograde cardioplegia; no selective cardioplegia, which is a complicated procedure, is required; continuous perfusion can prevent myocardial ischemia; and cannulation of the ascending aorta can be selected if femoral cannulation is not possible.

Meanwhile, the disadvantages of this surgery are as follows: right atrium incision and cutting of the fourth costal cartilage are required, and hemofiltration is often performed in cardiopulmonary bypass for potassium control because the volume of cardioplegic solution is high.

\section{Conclusion}

MICS-AVR via anterior thoracotomy using continuous retrograde cardioplegia is a safe technique.

\section{Disclosure Statement}

None.

\section{References}

1) Bezon E, Choplain JN, Khalifa AA, et al. Continuous retrograde blood cardioplegia ensures prolonged aortic cross-clamping time without increasing the operative risk. Interact Cardiovasc Thorac Surg 2006; 5: 403-7.

2) Yamazaki M, Kin $H$, Kitamoto $S$, et al. Efficacy of the Stonehenge technique for minimally invasive aortic valve replacement via right infraaxillary thoracotomy. Ann Thorac Surg 2017; 23: 45-8.

3) van Putte BP, Vink A, De Bruin PC, et al. Selective antegrade cardioplegic perfusion complicated by left main stem dissection. J Cardiovasc Surg 2007; 48: 247-8.

4) Yates JD, Kirsh MM, Sodeman TM, et al. Coronary ostial stenosis, a complication of aortic valve replacement. Circulation 1974; 49: 530-4.

5) Louagie YA, Gonzalez E, Jamart J, et al. Assessment of continuous cold blood cardioplegia in coronary artery bypass grafting. Ann Thorac Surg 1997; 63: 689-96.

6) Higami TOK, Asada T. Protective effect of the retrogradely perfused cold blood cardioplegia to the right ventricular myocardium. Electron microscopical study of mitchondoria. Jpn J Cardiovasc Surg 1989; 19: 527-9.

7) Daimon $\mathrm{M}$, Watanabe $\mathrm{H}$, Abe $\mathrm{Y}$, et al. Normal values of echocardiographic parameters in relation to age in a healthy Japanese population: the JAMP study. Circulation 2008; 72: 1859-66. 